\title{
Early cancer of the gastric remnant
}

\author{
R POINTNER, G SCHWAB, A KÖNIGSRAINER, E BODNER, \\ AND K W SCHMID \\ From the II Department of Surgery, I Department of Surgery, and Department of Pathology, University of \\ Innsbruck, Austria
}

\begin{abstract}
SUMMARY Early carcinoma of the gastric remnant was diagnosed in 19 patients between January 1976 and January 1986. In all patients early cancer was suspected at endoscopy and confirmed by biopsy and histology. The main reason for endoscopic examination was diffuse epigastric pain suggestive of stump gastritis. The surgical procedure was stump gastrectomy. Two of the 19 patients were not operated on because of advanced age. In contrast with the poor prognosis of patients with cancers of the gastric remnant of tumour stages $T 2$ to $T 4$ according to the TNM-classification regardless of their NM-stage, patients with tumour stage T1NO and T1N1 have a good prognosis.
\end{abstract}

Cancer in the operated stomach was first described by Balfour' in 1922. It is defined as a carcinoma detected more than five years after surgery for a benign disease. Gastric stump carcinoma seems to be diagnosed mainly in an advanced stage and the prognosis is unfavourable as compared with the cancer in the non-operated stomach. ${ }^{2}$ Thus, early detection of the gastric stump cancer seems to be rare, and there is little reported about the incidence. ${ }^{34}$

Verse ${ }^{5}$ was the first to describe a 'gastric mucosal cancer' in 1908. Since that time the detection of these malignant lesions of the gastric mucosa has increased steadily. In 1962 the Japanese Society of Endoscopy called the mucosal stages of gastric carcinoma 'early gastric cancer'. It is defined as a cancer limited to the submucosa, with or without regional lymph node metastases. This mucosal type of cancer may occur in a non-resected stomach as well as in a gastric remnant as a 'stump carcinoma'. The frequency of the early gastric cancer varies in the different countries, ranging from about $35 \%$ in $\mathrm{Japan}^{6}$ to less than $10 \%$ within all gastric cancers in Europe. ${ }^{7}$ Although in Japan mass screening led to an increased detection of malignant mucosal lesions, the possibility of detecting early cancer in the gastric remnant still gives rise to controversy. ${ }^{8-12}$

Address for correspondence: Dr Rudolph Pointner, II Univ Klinik für Chirurgie, Anichstrasse 35, A-6020 Innsbruck, Austria.

Received for publication 4 September 1987.

\section{Methods}

PATIENTS AND CLINICAL FEATURES

Between January 1976 and January 1986137 carcinomas of the gastric remnant were diagnosed at our Hospital. Nineteen cases, that is $14 \%$ of all stump carcinomas, were early cancers of the mucosal or submucosal type. The male/female ratio was 16 to 3 ; patients ranged in age from 43 to 88 years, eight were older than 70 years.

\section{CLINICAL SYMPTOMS}

In none of the 19 patients did clinical symptoms lead to the diagnosis of early gastric carcinoma. The symptoms were vague, often only consisting of a sensation of epigastric fullness or indigestion. Nonspecific epigastric pain was common. It is remarkable, that none of the patients had a loss of weight, whereas ill defined complaints had been present up to one year before endoscopy (Table 1). In most cases patients were not admitted to our Hospital because of the symptoms listed in Table 1. Often these complaints were noted accidentally and led to an endoscopic examination of patients with a gastric remnant. Fourteen of the 19 patients were smokers (15-30 cigarettes/day), nine patients drank occasionally, four patients regularly drank beer and/or wine. Endoscopical examination was strongly recommended to all patients with previous Billroth $I$ or Billroth II resection, even if they were admitted to the hospital with complaints not related to the gastric remnant. Endoscopical examination started at the 
Table 1 Data and clinical symptoms of all patients of this study

\begin{tabular}{llllll}
\hline $\begin{array}{l}\text { Sex/year } \\
\text { of birth }\end{array}$ & $\begin{array}{l}\text { Time } \\
\text { lag }\end{array}$ & $\begin{array}{l}\text { Weight } \\
\text { loss }\end{array}$ & $\begin{array}{l}\text { Lossof } \\
\text { appetite }\end{array}$ & $\begin{array}{l}\text { Sensation } \\
\text { offullness }\end{array}$ pain \\
\hline $1 \mathrm{~m} / 1910$ & 34 & - & - & - & - \\
$2 \mathrm{~m} / 1929$ & 16 & - & + & + & + \\
$3 \mathrm{~m} / 1919$ & 23 & - & + & + & + \\
$4 \mathrm{f} / 1896$ & 45 & - & - & - & + \\
$5 \mathrm{~m} / 1901$ & 50 & - & - & - & + \\
$6 \mathrm{f} / 1894$ & 35 & - & - & - & + \\
$7 \mathrm{~m} / 1908$ & 32 & - & + & + & + \\
$8 \mathrm{~m} / 1906$ & 30 & - & - & - & - \\
$9 \mathrm{~m} / 1915$ & 26 & - & - & + & + \\
$10 \mathrm{f} / 1899$ & 46 & - & + & + & + \\
$11 \mathrm{~m} / 1917$ & 6 & - & - & + & + \\
$12 \mathrm{~m} / 1935$ & 14 & - & - & + & + \\
$13 \mathrm{~m} / 1912$ & 26 & - & - & - & - \\
$14 \mathrm{~m} / 1913$ & 36 & - & + & + & + \\
$15 \mathrm{~m} / 1895$ & 42 & - & + & - & + \\
$16 \mathrm{~m} / 1939$ & 22 & - & - & - & + \\
$17 \mathrm{~m} / 1942$ & 24 & - & - & - & + \\
$18 \mathrm{~m} / 1922$ & 11 & - & + & + & + \\
$19 \mathrm{~m} / 1926$ & 29 & - & - & - & + \\
\hline
\end{tabular}

*Time lag between Billroth I or Billroth II resection and diagnosis of early gastric cancer.

latest 15 years after gastric surgery. Subsequent follow up examinations depended on endoscopical and/or histological findings.

DIAGNOSIS

In all 19 patients the exact diagnosis was established by means of endoscopy in conjunction with biopsy. In 10 cases there was a strong suspicion of a malignant tumour at endoscopy, in nine cases the endoscopic aspect of the lesion was indeterminate. In all cases the final diagnosis of early gastric carcinoma was made on histological examination of biopsies of suspicious lesions. In three cases a second endoscopy was required to establish an accurate diagnosis because unsatisfactory material was obtained at the first histologic examination. In 11 patients a radiographic examination was done before the endoscopic examination, but only in one case was the radiological appearance of the mucosa identified as malignant (Table 2).

Table 2 Examiner's judgment

\begin{tabular}{lllc}
\hline & Benign & Indeterminate & Malignant \\
\hline Radiography & 5 & 5 & 1 \\
Endoscopy & - & 9 & 10 \\
Biopsy & - & - & 19 \\
Surgical specimens & & 3 & 9 \\
$\quad$ Gross evidence & 5 & - & 17 \\
$\quad$ Histological evidence & - & & \\
Not operated: $2^{*}$ & & & \\
\hline
\end{tabular}

${ }^{*}$ Early carcinoma confirmed at subsequent necropsy.
LOCATION AND TYPES

As shown in Figure 1, the lesser curvature is the predominant location of early gastric stump cancer. According to the histological classification of Lauren ${ }^{13} 15$ carcinomas of the intestinal and four of the diffuse infiltrating type were found. Table 3 shows the distribution of the macroscopical appearances of early cancer based on the Japanese Classification;' the marked prevalence of the protruded over the excavated forms is evident. Multicentricity of the lesions could not be observed in our cases.

\section{Results}

\section{SURGICAL MANAGEMENT}

In 16 patients the previous operation for benign gastric or duodenal ulcer disease had been a gastric resection according to the Billroth II method, three patients had undergone Billroth I resection. Duration between the first operation and diagnosis of early gastric carcinoma can be seen in Table 1 . Two patients with a Billroth II, did not undergo surgery for early stump carcinoma because of their advanced age (over 80 years); in 15 patients total gastrectomy of the stump was carried out; in two cases the anastomosis and lower part of the Billroth I-stomach was resected and converted to a Billroth II. All operated patients made an uncomplicated postoperative recovery. Figure 2 shows that after discharge from hospital no cancer related deaths occurred. The follow up period ranged from 13 months to 10 years, with a mean of five years. Survival times and causes of death for each patient are seen in Figure 2.

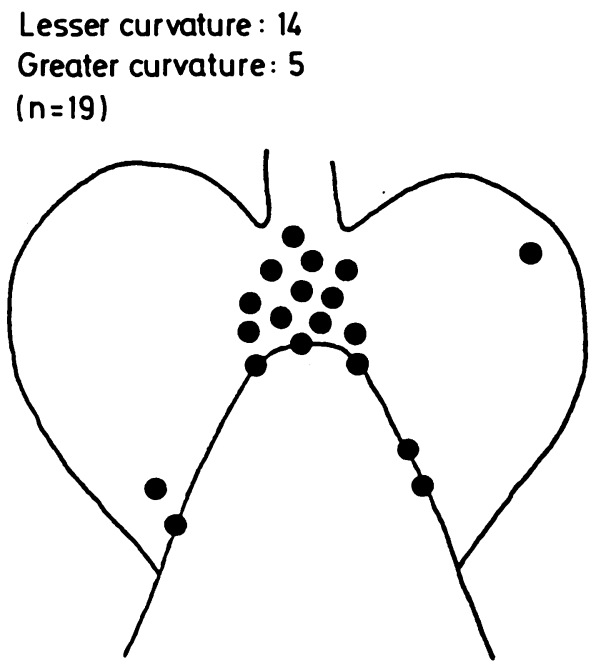

Fig. 1 Location of early cancers in the gastric remnant in the endoscopical examination $(n=19)$. 


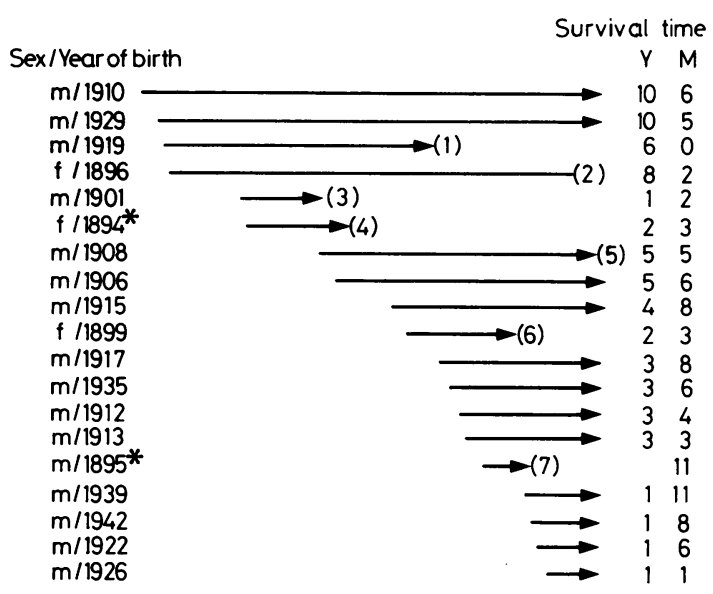

$\begin{array}{lllllllllll}1976 & 77 & 78 & 79 & 80 & 81 & 82 & 83 & 84 & 85 & 86\end{array}$

Causes of death: (1)= Bronchial carcinoma $(2)=$ Apoplectic insult, $(3)=$ Myocardial infarct, $(4)(6)$ and $(7)=$ Cardiac insufficiency, $(5)=$ Accident $\quad *=$ No operation

Fig. 2 Follow up and survival time of all patients $(n=19)$.

\section{Discussion}

Since the mid-1950s an increasing number of patients suffering from gastric remnant cancer have been reported. ${ }^{9101214}$ Although gastric stump cancer is regarded as a distinct entity, ${ }^{15}$ there is little known about early carcinoma in the gastric stump. ${ }^{34}$ The depth of penetration by the tumour into deeper layers of the stomach wall is closely related to the survival time of patients. ${ }^{16}$ The five year survival rate of patients with early gastric cancer is reported in the literature worldwide as over $90 \% .{ }^{17-19}$ The survival rate of patients suffering from cancer in the gastric stump is less favourable compared with cancer in the non-resected stomach ${ }^{12} 15$ and probably related to the late detection of the malignant lesion.

According to Logan and Langman ${ }^{8}$ and Sonnenberg ${ }^{20}$ there seems to be statistical evidence that meticulous follow up of patients with a previous Billroth I or Billroth II resection does not increase the detection rate of stump cancers whereas Clark and coworkers recommended in a major review of cancer after gastric surgery ${ }^{21}$ endoscopical screening for patients under 70 years treated by gastric surgery 15 years or more previously, and for those under 55 treated by gastric surgery 10 years previously. Our 19 cases of early cancers of the gastric remnant were found by rigorous endoscopic examination beginning at the 15th year after previous gastric surgery. We are fully aware that we cannot prevent stump carcinoma by this practice, however, it does allow detection at a still curable stage. The fact that $14 \%$ of the stump carcinomas diagnosed at our hospital over the last 10
Table 3 Histological typing of early cancers of the gastric remnant

\begin{tabular}{lr} 
Japanese Classification: & 10 \\
Type I (protruded type) & 4 \\
Type IIA (superficial raised type) & 3 \\
Type IIB (superficial flat type) & 1 \\
Type IIC (superficial depressed type) & 1 \\
Type III (excavated type) & 15 \\
Lauren Classification: & 4 \\
Intestinal type & 16 \\
Diffuse infiltrating type & 1 \\
Lymph nodes: & 2 \\
Tumorfree & \\
Metastases & \\
Not operated & \\
\hline & Early carcinoma confirmed at subsequent autopsy.
\end{tabular}

years were identified as early cancers as compared with $16 \%$ in the non-resected stomach, suggests that early detection of gastric cancer should be aimed at in both cases. The time lag between diagnosis and previous surgery varies between six and 50 years with a mean value of 29 years, which is approximately the same as in advanced stump cancer ( 27 years). ${ }^{2}$

Patients with advanced cancer of the gastric remnant commonly present with the following symptoms: sensation of epigastric fullness, lack of appetite and rapid weight loss are reported in almost $100 \%$. Symptoms of patients with early gastric cancer are postprandial pain, nausea, and fasting epigastric disorders. The most common symptom of early gastric stump cancer is non-specific epigastric pain similar to patients suffering from stump gastritis. In the first instance, no distinctive clinical laboratory or radiographic feature distinguishes reliably the patients with early cancer from those with stump gastritis. Both macroscopically and histologically, severe mucosal changes characteristic of stump gastritis were found in all 19 cases in association with the early cancer. It must therefore be pointed out that it is still not clear whether symptoms of stump gastritis or those of early gastric stump cancer may have been the reason for screening and subsequent diagnosis of early gastric stump carcinoma. The question whether or not stump gastritis can become malignant is still unresolved. Considering the known relationship between gastric carcinoma and intestinal metaplasia or dysplasia, ${ }^{10114}$ a close relationship between these mucosal changes and early carcinoma of the gastric stump could be postulated.

The method of choice for the clinical diagnosis of early gastric stump cancer is endoscopy. If the macroscopic evaluation causes the endoscopist to suspect malignancy, although the histology of the biopsy specimen is negative, another biopsy should be performed. In three of our patients a second 
biopsy was required to verify an endoscopic tentative diagnosis. As can be seen in Table 2, x-ray examination plays a minor role in the early detection of gastric stump cancer.

The number of 16 patients with an early stump cancer found in a Billroth II resected stomach compared with three cases found in a Billroth I resected stomach reflects that up to the mid-1960s almost exclusively Billroth II resections were carried out in our hospital. It is of interest that the three patients with Billroth I resected stomach were operated on in the last 20 years in which Billroth I resections increased steadily to $50 \%$ of all resections of the stomach (patients 11, 16, and 18, see Table 1).

As in the upper third of the unresected stomach, the protruded forms (type I, type IIa) according to the Japanese Classification of early carcimona ${ }^{7}$ also prevail in the gastric remnant: 14 of 19 cases were diagnosed as type I or IIa forms.

Seventeen of 19 patients with early carcinoma of the gastric remnant underwent surgery. The surgical management is in accordance with the procedure applied in cases of advanced stump cancer: based on the general principle of gastric cancer surgery, it aims at gastrectomy. The same applies to lymph node dissection.

All patients made an uneventful postoperative recovery. After discharge from hospital, no death occurred in relation to the previous malignant lesion. Thus, the five year survival rate of these patients is excellent (Fig. 2). The two patients who were not operated on because of their advanced age died from cardiac failure two and a half years and one year respectively after diagnosis. In both necropsy showed that the lesion in the gastric remnant was still an early carcinoma, corresponding with the description of the endoscopist in both type and size. Apparently no tumour growth had occurred in these two 80 year old patients during follow up. According to our results, early carcinoma of the gastric remnant has a considerably better prognosis compared with tumours of advanced stages. Considering that permanent cure can only be achieved by early diagnosis and operation - just as in cases of 'normal' early carcinoma - we try to detect stump cancer at a curable stage and to assess the risk of developing cancer in the gastric remnant.

We would like to express our sincere gratitude to $\mathrm{Dr}$ G T Williams, University of Wales College of Medicine, Cardiff, UK, for his helpful advice during the preparation of this paper.

\section{References}

1 Balfour DC. Factors influencing the life expectancy of patients operated on for gastric ulcer. Ann Surg 1922; 76: $405-8$.
2 Schwamberger K. Zur therapie und Prognose des Magenstumpfkarzinoms. In: Brinte $\mathrm{H}$, ed. Aktuelle Therapie des Magenkarzinoms. Berlin: Springer Verlag, 1985: 135.

3 Rehmer M, Soekendra N, Eichfuß HP, Dahm K, Eckert $\mathrm{P}$, Mitschke H. Frühkarzinome im Billroth IIResektionsmagen. Dtsch Med Wochenschr 1974; 99: 533-4.

4 Offerhaus GJA, Huibegtse K, De Boer J, Verhoeven T, van Olffen GH. The operated stomach: A premalignant condition. A prospective endoscopic follow-up study. Scand J Gastroenterol 1984; 19: 521-4.

5 Versé M. Über die entstehung, den bau und das Wachstum der Polypen, Adenome und karzinome des Magendarmkanals. Arb Pathol Inst Leipzig 1908; 1: 40-74.

6 Shimamoto K, Nakajiama M, Tomaka Y, et al. Das Magenfrühkarzinom - aktuelle Entwicklung in Japan. Leber-Magen-Darm 1984; 14: 1-7.

7 Schlag P, Merkle P, Altunbay S. Das Magenfrühkarzinom. Chir Praxis 1981; 28: 245-53.

8 Logan RFA, Langman MJS. Screening for gastric cancer after gastric surgery. Lancet 1983; ii: 667-9.

9 Denck H, Salzer G. Die Frage der Karzinomgefährdung des Ulkuskranken und Magenresezierten. Gastroenterologia 1957; 88: 94-109.

10 Fischer $\mathrm{AB}$, Graem N, Jensen OM. Risk of gastric cancer after Billroth II resection for duodenal ulcer. $\mathrm{BrJ}$ Surg 1983; 70: 552-4.

11 Schrumpf E, Stadaass J, Myren J. Mucosal chances in the gastric stump 20-25 years after partial gastrectomy. Lancet 1977; ii: 467-9.

12 Hilbe G, Salzer GM, Hussl H. Die Karzinomgefährdung des Resektionsmagens. Langenbecks Arch 1968; 323: $142-53$.

13 Lauren P. The two histological main types of gastric carcinoma: diffuse and so-called intestinal type carcinoma; an attempt at a histoclinical classification. Acta Pathol Microbiol Immunol Scand, Sect A: 1965; 64: 31-49.

14 Domelöff L, Erikson S, Janunger KG. Carcinoma and possible precancerous changes of the gastric stump after Billroth II resection. Gastroenterology 1977; 73: 462-8.

15 Morgenstern L, Yamakava T, Seltzer D. Carcinoma of the gastric stump. Am J Surg 1973; 125: 29-38.

16 Yamada E, Miyaishti S, Nakazato H, Kato K, Kito T. The surgical treatment of cancer of the stomach. Int Surg 1980; 65: 387-99.

17 Miller G, Froelicher P, Kaufmann M, Maurer W. 10 years endoscopic diagnosis of early gastric cancer in Europe. J Cancer Res 1979; 93: 99-107.

18 Abe S, Ogawa Y, Nagasue N, et al. Early gastric cancer: results in a General Hospital in Japan. World J Surg 1984; 8: 308-14.

19 Dobroschke J, Schwemmle K, Hermanek P, Rösch W. Therapie-Ergebnisse beim Magenfrühkarzinom. Dtsch Med Wochenschr 1976; 101: 1904-12.

20 Sonnenberg A. Endoscopic screening for gastric stump cancer - would it be beneficial? Gastroenterology 1984; 87: 489-95.

21 Clark CG, Fresini A, Gledhill T. Cancer following gastric surgery. BrJ Surg 1985; 72: 591-4. 